\title{
LA CONSTRUCCIÓN DEL RETABLO MAYOR DEL REAL MONASTERIO DE SANTIAGO DE UCLÉS Y SUS ARTÍFICES
}

\author{
SONIA JimÉnEZ HoRTELANO ${ }^{1}$ \\ Universitat de València
}

\begin{abstract}
El retablo del convento de Santiago de Uclés fue sin duda, el gran exponente del retablo barroco cortesano en el ámbito conquense. Esta pieza, de inestimable valor artístico, fue mutilada y destruida en el contexto de la Guerra Civil española y prácticamente olvidada por la historiografía artística. En este artículo, a partir del análisis de documentación gráfica conservada, la comparativa con obras similares y el estudio de fuentes documentales inéditas recompondremos el proceso de construcción de este objeto mueble y de los artistas que intervinieron en su construcción. De igual modo, contextualizaremos la fabricación de esta obra dentro de la tipología de retablo en la que se enmarca y las motivaciones del monasterio santiaguista por contar con una obra de estas características.
\end{abstract}

Palabras clave: Retablo barroco; Francisco Rizi; Juan de Lobera; Ignacio Fox; Uclés; Orden de Santiago.

\section{THE CONSTRUCTION OF THE MAIN ALTARPIECE OF THE ROYAL MONASTERY} OF SANTIAGO DE UCLÉS AND ITS CRAFTSMEN

The altarpiece of the convent of Santiago in Uclés was without doubt, the greatest example of the Court Baroque altarpiece in the Cuenca area. This piece of inestimable artistic value was mutilated and destroyed during the Spanish Civil War and almost forgotten by art historians. The aim of this paper is to recompose the process of construction of this work and its craftsmen, with the aid of preserved graphic documentation, comparison with similar works and the study of unpublished documentary sources. Likewise, the author contextualizes the fabrication of this piece within other works of the same typology and considers the motivations of the monastery to commission a work of these characteristics.

Key words: Baroque altarpiece; Francisco Rizi; Juan de Lobera; Ignacio Fox; Uclés; Order of Saint James.

Cómo citar este artículo / Citation: Jiménez Hortelano, Sonia (2018): "La construcción del retablo mayor del Real Monasterio de Santiago de Uclés y sus artífices”. En: Archivo Español de Arte, vol. 91, núm. 364, Madrid, pp. 381-394. https://doi.org/10.3989/aearte.2018.23.

En una fecha imprecisa, entre 1892 y 1930, el ojo de la cámara estereoscópica de Aurelio de Colmenares y Orgaz, conde de Polentinos (Madrid, 1873-1947), inmortalizó la desaparecida obra del retablo de Uclés (fig. 1). Poco después, durante la Guerra Civil y tras el posterior uso como cárcel franquista del monasterio, el retablo original y sus piezas (a excepción del lienzo central de Francisco Rizi) desaparecerían, llevándose consigo parte de un relato que, gracias a esta investigación, nos proponemos recomponer ${ }^{2}$.

\footnotetext{
1 sonia.jimenez@uv.es / ORCID iD: http://orcid.org/0000-0002-3973-1914.

2 Este trabajo ha sido realizado gracias a una beca de Formación de Profesorado Universitario (FPU) concedida por el Ministerio de Educación para la realización de la tesis doctoral, enmarcada en el proyecto I+D del Ministerio de
} 

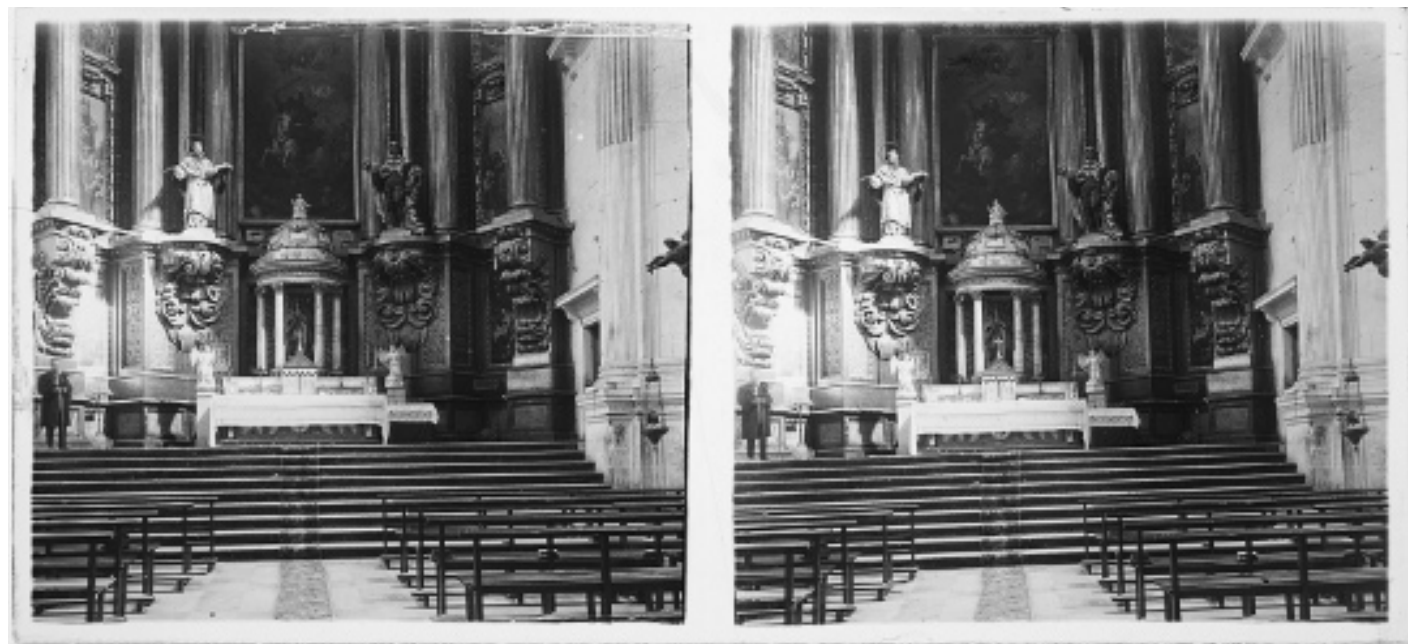

Fig. 1. Aurelio de Colmenares y Orgaz, conde de Polentinos. Fotografía estereoscópica del retablo mayor de Uclés. Principios del siglo XX. Archivo Conde de Polentinos DCP-A-3736, Instituto del Patrimonio Cultural de España, MECD.

En 1529, pocos años después de la coronación de Carlos V como rey de romanos se iniciaba la remodelación del antiguo convento medieval de los caballeros de Santiago en Uclés. A finales de la centuria la iglesia estaba prácticamente concluida, y durante los primeros años del siglo XVII se comenzó a trabajar en el proyecto de la construcción del retablo que debía presidir el altar mayor. La primera noticia relativa a esta iniciativa se produce en 1602, cuando el escultor y arquitecto Juan Bautista Monegro forma compañía con el escultor de Penagos Toribio González de la Sierra, para contratar la obra retablo y la sillería del convento de Uclés ${ }^{3}$. La compañía entre estos dos artífices se mantuvo también, al menos sobre el papel, para la realización de los retablos de las cercanas parroquias santiaguistas de Villarejo de Salvanés y Colmenar de Oreja, entra otras ${ }^{4}$. El retablo proyectado para Uclés debió estar en consonancia con los modelos clásicos y severos de El Escorial que Monegro implantó en Toledo ${ }^{5}$. Sin embargo, este ambicioso proyecto nunca vería la luz, ya que en 1611 los visitadores del convento se lamentaban de la ausencia total de retablos en el templo para el desarrollo normal de la liturgia, situación que se mantendría hasta casi media centuria después ${ }^{6}$. Tendremos que avanzar hasta la década de los sesenta del siglo XVII para que el convento se decida a retomar el proyecto del retablo mayor. Este lapso de tiempo puede entenderse debido a la fluctuación irregular de las rentas del convento y a la inversión económica necesaria en aquellos años para la finalización de la obra del conjunto monástico, que por aquel momento avanzaba por la panda oeste.

Ciencia e Innovación (HAR2014-54751-P), “Ecos culturales, artísticos y arquitectónicos entre Valencia y el Mediterráneo en Época Moderna".

3 Marías, 1985: 176. González/Aramburu-Zabala/Alonso/Polo, 1991: 276.

${ }^{4}$ La colaboración entre estos dos artífices es habitual en el ámbito toledano. En 1589 González contrató la obra de dos retablos laterales de San Juan de los Reyes que Monegro había trazado, unión que se repetiría en el retablo mayor de la concepción francisca un año después. Este tipo de colaboraciones en las que González era seguidor de Monegro, se prolongaría también al ámbito arquitectónico en obras como la del Alcázar o la remodelación de la iglesia de santos Justo y Pastor de Toledo de la que además ambos eran cofrades. Marías, 1986: 16.

5 Marías, 1985: 146.

${ }^{6}$ Lo mismo ocurría en las capillas colaterales de la iglesia "advirtiendo que a el presente no ay en el convento un solo quadro que pueda suplir en el entretanto que se hacen los retablos". Visita secreta al convento de Uclés, 1611. Archivo Histórico Nacional (AHN), Órdenes Militares, Archivo Secreto, Leg. 7015, fol. 1v. 
Todos los proyectos artísticos comisionados por el convento, desde la adquisición de objetos litúrgicos hasta las obras de reconstrucción, quedaron siempre subordinados a la capacidad económica del cenobio, condicionada en gran medida por la bonanza de las cosechas de las que el convento se beneficiaba ya fuera directamente o a través del cobro de diezmos. Es evidente que los bajos ingresos de la primera mitad del siglo XVII y la necesidad de concluir las obras arquitectónicas del propio monasterio también en marcha, habían retrasado la construcción del retablo que debía presidir el altar mayor. Sus grandes dimensiones y el esperado carácter monumental del mismo presagiaban la necesidad de una importante inversión económica.

A mediados de los años sesenta la necesidad era manifiesta. Sorprendentemente y al margen de lo que venía siendo habitual, podemos afirmar que en este caso la construcción del retablo mayor barroco sí gozó de la aportación económica de al menos, un privado. Santiago Francisco Zapata y Mendoza, vecino de Madrid, caballero de la Orden de Santiago y caballerizo de su Majestad con preeminencia de bosques se encontraba en Uclés el 27 de marzo de 1665, cuando estando enfermo, se decidió a redactar testamento. En sus últimas voluntades, este caballero expone cómo debía distribuirse su hacienda, de la que, una vez repartida, hacía como heredero universal al Real Convento de Uclés del remanente que quedara, dejando claramente especificado que el dinero debía utilizarse para ayuda de hacer el retablo mayor ${ }^{7}$. Aunque este documento no especifica la cantidad exacta que se destinaría para la realización del retablo, creemos que esta debió ser entendida como un considerable impulso para la construcción del tan esperado mueble. A partir de esta fecha se pondría en marcha la maquinaria del convento con miras a conseguir una traza apropiada para su construcción ${ }^{8}$. En este sentido, entraría en juego el papel del agente de negocios del que sabemos que disponía el convento en la corte. Este tipo de personajes, poco estudiados todavía en el ámbito conventual, servirían de nexo artístico entre diferentes centros "satélites" entorno al foco artístico por excelencia de Madrid. Así, los monjes reunidos en capítulo establecían las instrucciones generales que eran enviadas a la persona representante del convento en el círculo regio. Gracias a la mediación de estos agentes, además de conseguirse la intervención en aspectos judiciales o de diversa índole, el convento se mantenía al tanto de las tendencias artísticas del entorno real, encargando siempre que fuera posible, objetos que respondieran a esas mismas exigencias.

\section{La construcción del retablo y sus artífices}

Gracias a diversos documentos gráficos de principios del siglo XX podemos apreciar la magnificencia del retablo barroco no conservado (fig. 2). El proyecto tenía en cuenta el ábside poligonal con el que se había cerrado la cabecera del templo durante la primera mitad del siglo XVI, por lo que se optó por la tipología de retablo ochavado, rematado con un cascarón de cuarto de esfera, al modo del que presidía la iglesia del hospital Tavera en Toledo, protegiendo a diferencia de aquel, un tabernáculo en forma de templete en el primer nivel que albergaba la escultura de

\footnotetext{
7 " [...] y del remanente que quedare y fincare de todos mis bienes muebles raíces derechos y acciones de lo instituido y nombro por mi lejítimo y universal heredero de todos ellos a el Real Combento de Santiago susodicho para que los aya y goze para siempre jamás sin contradizión alguna para que con ellos y su valor se ayude a hazer el retablo mayor de él y con cargo y obligazión que a de tener dicho combento de hazer y decir para mi alma un aniversario y misa cantada en cada un año todos los días de san Francisco, quatro de octubre para siempre jamás perpetuamente cuya obligación a de costar desde el día que peziviere los dichos bienes". Testamento de Francisco Zapata y Mendoza. Archivo Notarial de Uclés (ANU), Libro 40, doc. 3, fol. 142r.

${ }^{8}$ Con motivo de la revisión de las cuentas del prior Bernabé Pizaño Gil Negrete (prior entre 1666 y 1669), Gregorio de la Torre, el religioso más antiguo "dijo que save a avido muchas mejoras y aumentos en la yglesia deste convento en la custodia que oy se ve puesta, con los acheros plateados, colgaduras y aver concertado y dado principio a la hechura del retablo, y en las demás capillas y altares y que así mismo están mejoradas las casas de recreaciones y de más edificios y en lo demás de la pregunta no save que aya faltado a cossa alguna de lo en ella contenido". Cuentas del prior Bernabé Pizaño Gil Negrete,1669. AHN, Archivo Histórico de Toledo, Leg. 64687.
} 


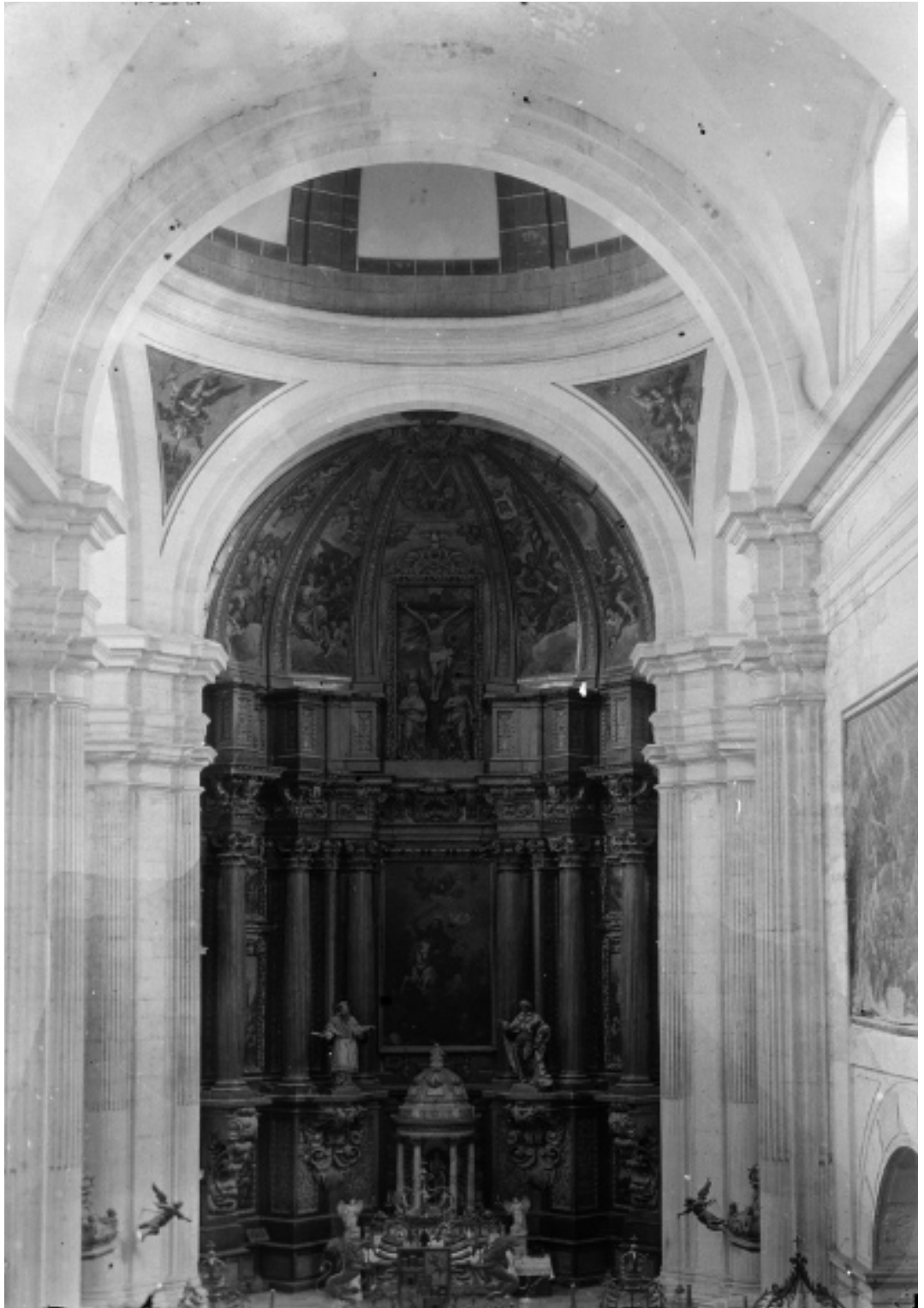

Fig. 2. Imagen

del altar mayor de Uclés. Principios del Siglo XX. Biblioteca Tomás Navarro Tomás del Centro de Ciencias Humanas y Sociales del Consejo Superior de Investigaciones Científicas. Archivo Orueta. CSIC. ATN/ $\mathrm{GMO} / \mathrm{sf1440.}$

la Inmaculada, advocación de especial devoción para los santiaguistas, firmes defensores del dogma.

Al igual que la iglesia conventual, el retablo estaba dotado de unas proporciones más que estimables. En altura, el retablo se organizó mediante un basamento pétreo del que arrancaban, a modo de plintos suspendidos, 6 altas columnas de capiteles compuestos, sosteniendo cada una de ellas su propio fragmento de entablamento del que despegan seis nervios que cierran el ochavo en forma semicircular. Los elementos vegetales y las hojas carnosas pasan en Uclés la barrera de lo meramente decorativo, para formar parte de lo estructural en el basamento del retablo, de tal forma que tanto las columnas como basas que sostienen las esculturas centrales parecen emerger de la propia vegetación. Igualmente llamativo, es el uso de pilastras acodadas entre las primeras y segundas columnas, en aras de resolver de forma satisfactoria la adaptación del retablo al espacio y al mismo tiempo la inclusión de pinturas laterales. 
Hasta ahora, pocos eran los datos con los que contábamos relativos al proceso constructivo o a los artífices que llevaron a cabo la obra del retablo. En realidad, la gran mayoría de los estudios publicados hasta la fecha se han servido de los datos que a finales del siglo XVIII aportaron los ilustrados Ponz y Ceán. Gracias a Ponz sabíamos que el autor material del retablo fue Francisco García Dardero, "natural de Quintanar, el año de 1668 y su costo fue de 9.500 ducados", añadiendo la información de que el cuadro que presidía el retablo que representaba a Santiago a caballo "es muy buena pintura de Francisco Rici, que la hizo el año de 1672 por el precio de mil ducados y seiscientos reales de guantes" de Llaguno quien atribuye la traza de este retablo al propio Francisco García Dardero, sin que sepamos qué motivó esta atribución y esta ampliación en la información con respecto a lo publicado por Ponz ${ }^{10}$. Sea como fuere, lo cierto es que esta autoría en las trazas ha sido tenida como cierta de forma prácticamente unánime por la historiografía, solamente cuestionada por Cruz Yábar en su tesis doctoral, como más adelante veremos.

Gracias a la documentación de archivo del convento de Uclés y en especial a los libros de cuentas del convento, hemos podido constatar que efectivamente, Francisco Garcia Dardero fue el autor material de la obra del retablo, en concreto de la labor de talla y ensamblaje del mismo ${ }^{11}$. Los pagos por su trabajo se extienden de manera más o menos regular en los libros de cuentas del convento aproximadamente entre 1668 y 1677, año en el que podríamos situar la finalización de la talla y ensamblaje. En realidad, contamos con pocos datos sobre la carrera artística de este Francisco García Dardero. Algunos autores han asociado la vecindad de García Dardero con Quintanar de la Orden, pueblo cercano a Uclés y perteneciente a su priorato ${ }^{12}$, si bien es posible que pueda identificarse con Francisco García, autor de retablos en el ámbito salmantino ${ }^{13}$. Como más adelante veremos, nos cuesta creer que, dada la importancia y calidad del proyecto, el convento no buscara en el ámbito de la corte las trazas necesarias para su construcción, como sí hizo a la hora por ejemplo de contratar las pinturas que debía contener.

\section{Las pinturas}

En 1672, cuando la obra del retablo debía estar ya lo suficientemente definida, el convento movilizó a su agente de negocios en Madrid para contratar el lienzo que presidiría la obra. El 16 de mayo de ese año el Capítulo del convento de Uclés entregó un poder a su agente Pascual García, mediante el cual se le otorgaba la capacidad de contratar con Francisco Rizi la obra del cuadro central, un poder al que acompañaba toda una serie de indicaciones sobre las características que debía tener el cuadro, si bien se le confería cierta capacidad operativa al agente para poder alterarlas. Las negociaciones entre ambas partes llegaron a buen puerto, de forma que el 24 de mayo Francisco Rizi:

"se obliga en bastante forma a hacer la dicha pintura de su propia mano, que ha de tener de alto diez y seis pies y medio y nuebe y medio de ancho, con una ystoria de la batalla de moros y cristianos en su seguimiento de manera que el cavallo de Santiago quede muy descubierto por todos lados; el qual se obliga a dar acabado en toda perfeción que pueda estar en el dicho com-

\footnotetext{
9 Ponz, 1777: 160.

${ }^{10}$ Llaguno/Ceán, 1829: 58.

11 Los pagos aparecen esparcidos en distintos libros de cuentas del monasterio. Durante el priorato de Bernabé Pizaño Gil Negrete se pagaron a Francisco García Dardero, maestro del retablo 24.614 reales y 5 maravedís. Cuentas del prior Bernabé Pizaño Gil Negrete, 1669. AHN, Órdenes Militares, Archivo Histórico de Toledo, Leg. 64687, fol. 145r. En las cuentas tomadas entre 1672 a 1675 García Dardero recibió dos pagos, uno de 2.756 reales y un segundo de 48.410 reales y 17 maravedís. Cuentas del prior Tomás Jiménez Crespo, 1675. AHN, Órdenes Militares, Archivo Histórico de Toledo, Leg. 8685, sin fol.

12 Martín, 1942: 21.

13 Pérez de Castro, 2000: 275. Cruz, 2013: 289.
} 
bento de Uclés para el día diez de agosto deste presente año de la fecha, y ha de ir firmado de su mano y con aprobazión de los demás pintores de su Magestad y otros que quisiere elegirse por parte del dicho real combento, en que digan que el precio de mil ducados que por él se le ha de pagar los vale" 14 .

Tal y como se recogía en el acuerdo, el 25 de mayo Francisco Rizi aseguraba ante notario haber recibido por parte de Pascual García 5.500 reales de vellón en cuenta de los mil ducados por los que se había contratado la pintura de Santiago ${ }^{15}$ y que se le acabaron de pagar el 14 de agosto de aquel mismo año ${ }^{16}$, entendemos que cumpliendo los plazos de entrega marcados por el convento probablemente con miras a su exhibición durante la festividad de la Asunción.

En realidad, no era la primera vez que Francisco Rizi recibía el encargo de pintar un cuadro de Santiago a caballo para presidir un retablo mayor de una iglesia de la Orden santiaguista. Hacia 1652 se habría encargado de realizar el lienzo de Santiago del retablo mayor de la iglesia homónima de Madrid, obra desaparecida cuya traza fue firmada por Pedro de la Torre y aprobada por el propio rey en agosto de 1642 coincidiendo con la reforma de la cabecera del templo proyectada por Juan Gómez de Mora ${ }^{17}$. De nuevo, hemos de tener presente la voluntad constante del monasterio de Uclés con establecer vínculos artísticos con la corte de Madrid. Buen ejemplo de ello sería el hecho de disponer de un agente de negocios en la capital y de contar en numerosas ocasiones con la presencia de maestros arquitectos del ámbito real a la hora de proceder en la propia edificación del convento. En este sentido no sería extraño pensar que el ejemplo de la iglesia santiaguista madrileña fuera tomado como referencia por el agente del convento, queriendo contar la casa madre de la Orden con un lienzo directamente conectado con la producción artística del entorno real y la capital, de mano del por entonces pintor del rey.

No cabe duda de la satisfacción que debieron sentir los religiosos de Uclés ante la llegada del cuadro de Rizi, ya que un año después, en reunión del capítulo del convento celebrada el 23 de mayo de 1673, se acordaba de nuevo encargar ciertas pinturas del retablo mayor de la iglesia conventual de nuevo con Francisco Rizi, "pintor de su Majestad" 18 . El acuerdo no especifica a qué pinturas se refiere, pero si atendemos al desarrollo constructivo de la obra podría pensarse que estas se corresponderían con los lienzos laterales del primer piso, de los que hasta ahora prácticamente no teníamos información. Sobre este aspecto y a partir de fotografías anteriores a la desaparición del retablo, ya Angulo lanzó la hipótesis de que estas pinturas pudieran haber sido elaboradas a la par que el retablo quizá de la mano del propio Rizi, como nosotros ahora confirmamos. Este autor identificó parte de los temas de estas pinturas como una posible Ascensión y la Venida del Espíritu Santo, San Miguel y un santo prelado de medio cuerpo, mientras que la zona superior estaba representada la Gloria con ángeles músicos ${ }^{19}$. De nuevo son las fuentes documentales las que arrojan luz sobre el programa pictórico del conjunto en su totalidad. Por

14 Poder del convento de Santiago de Uclés al agente de negocios Pascual García para contratar con Francisco Rizi la pintura del retablo mayor. Archivo Histórico Protocolos Madrid (AHPM), Protocolo 10.125, fols. 186r.-189r. Publicado por Cruz Yábar, revisado y editado por la autora. Cruz, 2013: 869.

15 Carta de pago a Francisco Rizi, 25 de mayo de 1672. AHPM, Protocolo 10.125, fol. 192r. Cruz, 2013: 871.

16 Carta de pago a Francisco Rizi, 14 de agosto de 1672. AHPM, Protocolo 10.125, f. 332r-332v. Cruz, 2013: 872.

17 Cruz, 2005: 155-156. Díaz, 2008: 283. Marqués del Saltillo, 1953: 144.Además de este caso, se puede destacar entre otras, la colaboración entre estos dos artífices en el retablo mayor de la iglesia de Orgaz, realizado en la década de los cincuenta. Nicolau, 2008: 471-474. También en el retablo de la Expectación de los Trinitarios Calzados de Madrid (1652-1656) o en la parroquial de Vallecas (1669-1670) entre otros. Lamas-Delgado, 2013: 358.

18 En el convento de Uclés en veinte y tres días del mes de maio deste año de mil seiscientos setenta y tres estando juntos a campana tañida en el coro de este convento como es uso y costumbre [...] pinturas del retablo: Ilustrísimo señor prior propuso que ia está tiempo de que las pinturas que para el retablo que para el altar maior de la yglesia del convento se hace, se iciesen que viese el capítulo las disposición [sic] que a esto se podía dar y fue determinado por auto capitular que se hiciesen por Riz pintor de su Magestad [cosido] Madrid, precediendo el concierto y que [cosido] de un precio moderado. Acta del capítulo del convento de Uclés celebrada el 23 de mayo de 1673. AHN, Órdenes Militares, Libro 1536, fol. 67r.-67v.

19 Angulo, 1962: 96. 


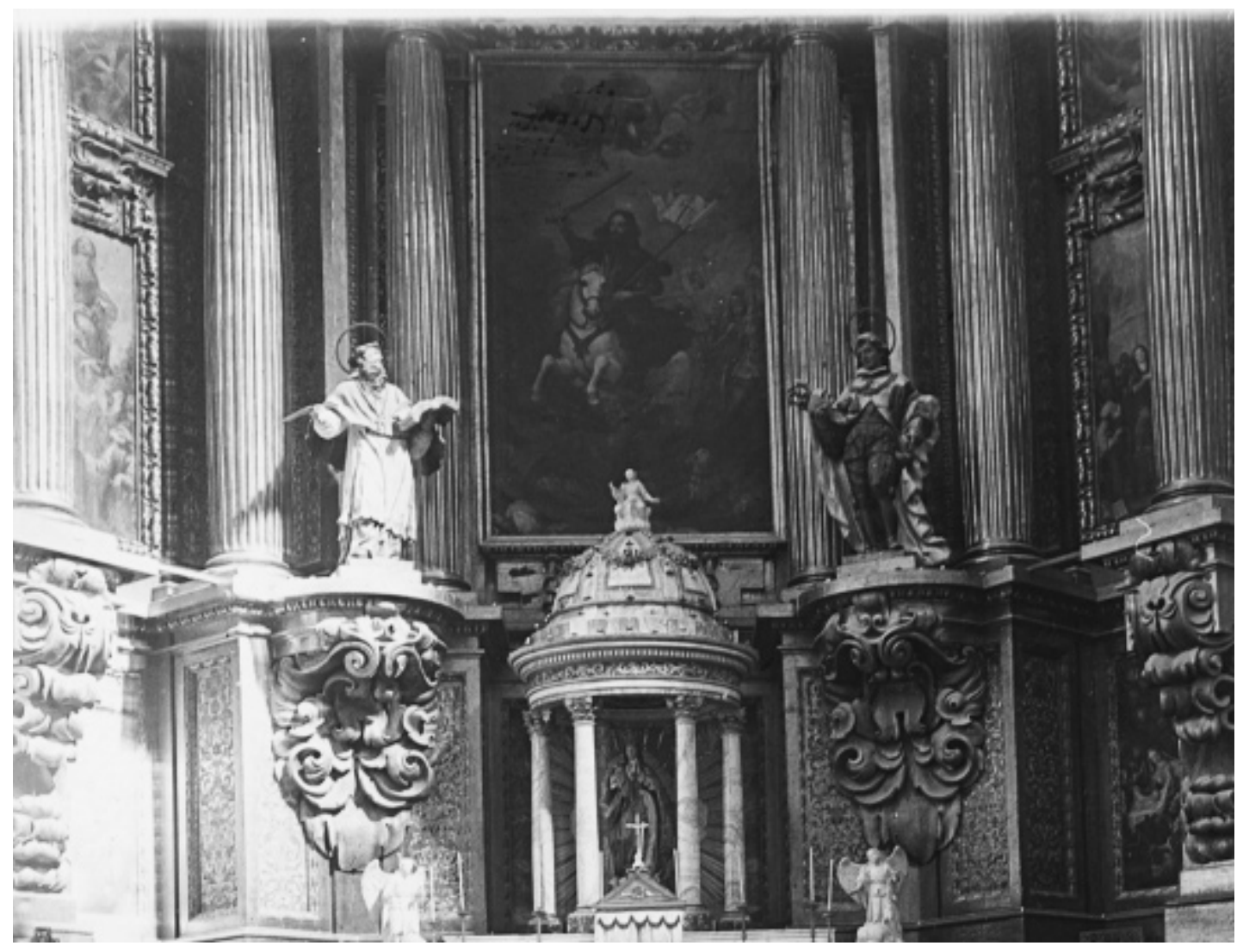

Fig. 3. Aurelio de Colmenares y Orgaz, conde de Polentinos. Fotografía estereoscópica del retablo mayor de Uclés (Detalle). Principios del siglo XX. Archivo Conde de Polentinos DCP-A-3736, Instituto del Patrimonio Cultural de España, MECD.

una visita efectuada en 1719, sabemos que los temas que aparecían en el retablo eran en el nivel bajo la Adoración de los Reyes y el Nacimiento ${ }^{20}$. Sobre estas, en el nivel superior en el lado del Evangelio La Transfiguración y arriba una imagen del arcángel San Miguel. En el lado contrario, la venida del Espíritu Santo y sobre ella una pintura de Santo Tomás ${ }^{21}$. Esta descripción coincide plenamente con la única fuente gráfica que ha llegado hasta nosotros, con la sufíciente calidad para apreciar las pinturas laterales. Nos referimos de nuevo a la fotografía obtenida por el Conde de Polentinos. La imagen, conservada hoy en el Instituto de Patrimonio Cultural de España muestra parcialmente las pinturas de la mitad inferior del retablo. Gracias a estas imágenes podemos apreciar una sintonía entre estas pinturas y la obra de Francisco Rizi, especialmente en las dos pinturas laterales de la venida del Espíritu Santo y la Transfiguración, recordando esta última en su composición al lienzo de la Traslación de María Magdalena de una colección particular palentina firmado de Rizi en 1674 localizado por Jesús Urrea (fig. 3$)^{22}$.

20 Según Martín Mayobre, los cuadros laterales del retablo de Torrejón de Velasco se correspondían con una Epifanía y la Navidad "atribuidos por varios expertos unánimemente y sin vacilaciones, a Claudio Coello". Martín, 1942: 22. Elías Tormo los atribuía a Coello o quizá más bien a Sebastián Martínez. Tormo, 1931: 419.

21 Visita al convento de Uclés, 1719. AHN, Órdenes Militares, Libro 1128c, fols. 8v.-9r.

22 Urrea, 1978: 500-502. Por otra parte, este lienzo ha sido puesto en relación con el desaparecido lienzo del mismo tema firmado por Rizi en 1674 para el retablo de la iglesia de Burguillos (Toledo). Pérez: 1986, p. 260. 
Además de decidirse la contratación de nuevas pinturas de la mano de Rizi y aunque el ensamblaje del retablo seguía en manos de García Dardero, en esta misma sesión del capítulo se acuerda la elaboración del pedestal por parte de Alonso Moreno, vecino de Toledo, el cual tenía firmadas ya unas condiciones para la elaboración del mismo ${ }^{23}$. Ante esta noticia cabría preguntarse sobre la personalidad de este Alonso de Moreno, para el que se contrata una obra muy específica en mármol muy diferente a la hechura en madera del retablo. Quizá pudiera tratarse de Alonso Moreno, hombre de confianza del que fuera maestro mayor de la catedral de Toledo Bartolomé Sombigo ${ }^{24}$ y que había participado en las obras del sagrario de la catedral de Sevilla así como en Marchena a partir de 1682, donde 3 años después fue nombrado tasador de la obra de mármol de gradas, pedestales, enchapaduras y portadas del retablo pétreo ${ }^{25}$. De tratarse de la misma persona, su presencia en el monasterio de Uclés sería significativa, ya que dejaría la puerta abierta a pensar que de alguna forma pudiera estar vinculado con la construcción arquitectónica del conjunto monacal, a pesar de que en este sentido no hemos encontrado otro tipo de documentación que corrobore esta hipótesis.

\section{Los autores de la traza}

En una sesión de actas de capítulo de la que no conservamos la página donde se indicaba y daba inicio la reunión, pero inmediatamente después de mayo de 1677 , se pone de manifiesto la conclusión de la obra del retablo en lo relativo al ensamblaje por parte de García Dardero. Este artífice presentó entonces ante los monjes reunidos, un memorial en el que se expresaban las mejorías del retablo ya colocado en el altar mayor. Según este informe, el precio de la madera para su construcción había sido mayor del previsto en el momento de contratar la obra, además de haberse elevado el precio de los jornales, por lo que declaró un aumento del coste de 15.000 reales. Ante lo expuesto, el capítulo conventual decidió conceder un aumento de 500 ducados, a condición de realizar un nuevo facistol para el coro, ya que el que en aquel momento había era de dimensiones excesivas y no "conforme a las sillas"26.

23 "Poder a los susodichos para ajustar la obra de el pedestral [sic] de el retablo con Alonso Moreno vecino de Toledo: Otro si dicho señor prior propuso al capítulo ser necesario dar poder alguna persona para ajustar el pedestral de el retablo y así que viese el capítulo que le pareçió y el capítulo respondió nemine discrepante que se diese (cosido) luego dicha, señor prior nombró a los dichos señores don Andres Portillo Baracaldo y a el licenciado Juan Crespo para que conçierten dicha obra con Alonso Moreno vecino de Toledo con las condiciones que el dicho tiene firmado y el capítulo lo otorgó". Acta del capítulo del convento de Uclés celebrada el 23 de mayo de 1673. AHN, Órdenes Militares, Libro 1536, fol. $85 \mathrm{v}$.

24 Madruga, 1983: 98.

Actúa como su hombre de confianza en la tasación de las obras en las Agustinas Recoletas de Salamanca en 1679. Madruga: 1983: 98. También había acompañado a Sombigo a visitar las obras de la iglesia-panteón de Marchena. Ravé, 1997: 259. Bartolomé Sombigo o Zumbigo fue un artífice que destacó por su conocimiento del trabajo del mármol. En la década de los sesenta fue llamado desde Madrid a Salamanca para montar las piezas que el conde de Monterrey, Manuel de Zúñiga y Fonseca había importado de Carrara en 1638 para uno de los retablos de las Agustinas Recoletas de la ciudad. Rodríguez, 1987-1988-1989: 228. Sobre la vida y obra de Sombigo ver: Rodriguez, 1988.

25 Herrera, 2012: 52.

26 "Gracia a Francisco García maestro del retablo: la obra del retablo que está en el altar maior de la iglesia de este dicho combento presentó un memorial que io el infraescrito secretario leí en dicho capítulo por mandado del señor prior en el qual representan a su señoría y capítulo las mexorías que avía hecho en dicha obra por cuia causa, averle costado la madera más de lo que se tasó para entrar en la dicha obra y por averse también subido los mantenimientos y jornales en el tiempo que duró avía sido alcançado en quinçe mil reales que en atención de lo referido le sirviese el capítulo de perdonarle alguna cantidad y los más de los capitulares resolvieron se le personasen quinientos ducados. Otrosí su señoría propuso y dixo como el facistol que ai en el coro embaraça demasiado y no es conforme a la obra de las sillas que en el ai que viese el capítulo si gustaba hiçiese otro Francisco Garcia a quenta de lo que resta deviendo de su alcançe y todos fueron de pareçer se hiçiese con otro remate que embaraçase menos a la vista de el altar maior que el que trae la planta que el dicho para este effecto a traido, sobre si dicho maestro avia de poner la madera o el combento ubo diversos pareçeres y se resolvió por la maior parte se hiçiese lo que más pareçiese cobeniente a el señor prior y maior- 
Fig. 4. Fotografía del desaparecido retablo de Torrejón de Velasco

(Madrid), principios del siglo XX. Archivo

Parroquial de la parroquia de San Esteban Protomartir de Torrejón de Velasco.

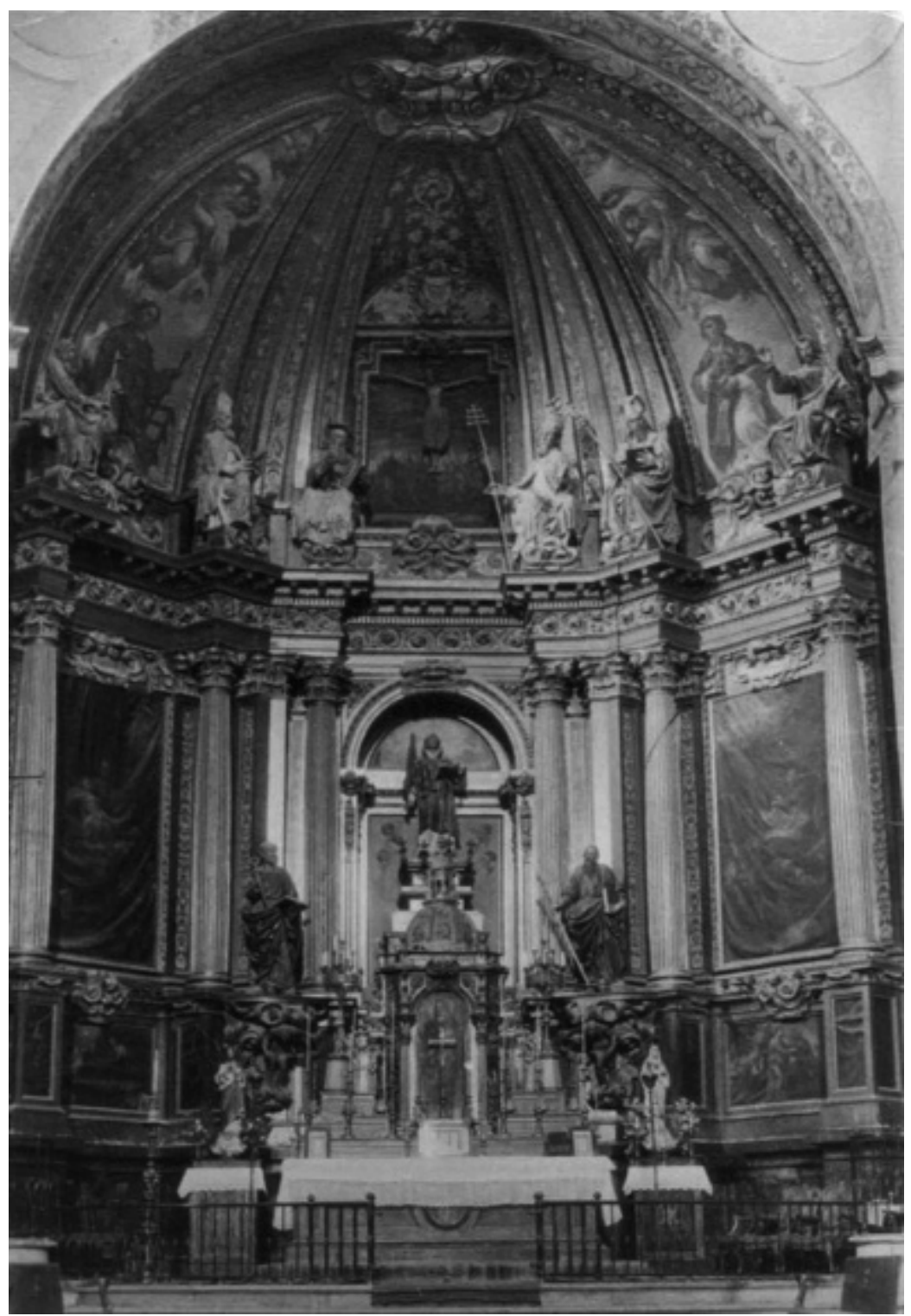

A pesar de que Francisco García Dardero fue el autor material del retablo, en nuestra opinión sería quizá cuestionable el que hubiera sido como decía Ceán, el autor de la traza. Si observamos las antiguas fotografías conservadas, no cabe duda de que el retablo de Uclés se inserta dentro de una tendencia que puede observarse en otros retablos del entorno de Madrid, como los de Navalcarnero, Pinto o el desaparecido de Torrejón de Velasco que ya señalara Ricardo Martín Mayobre (figs. 4 y 5) ) $^{27}$, realizado en lo fundamental entre los años de 1655 y $1672^{28}$ es decir, prácticamente coetáneo al de Uclés. Bajo nuestro punto de vista, la hipótesis que cobra mayor fuerza es, que de nuevo y como era habitual, el monasterio buscara a través de su agente en

domo". Acta de reunión del capítulo del convento de Uclés, sin fechar. AHN, Órdenes Militares, Libro 1536c. fol. $174 \mathrm{r}-174 \mathrm{v}$.

27 Martín, 1942: 21.

28 Martín, 1942: Cruz, 2003: 257-261. 


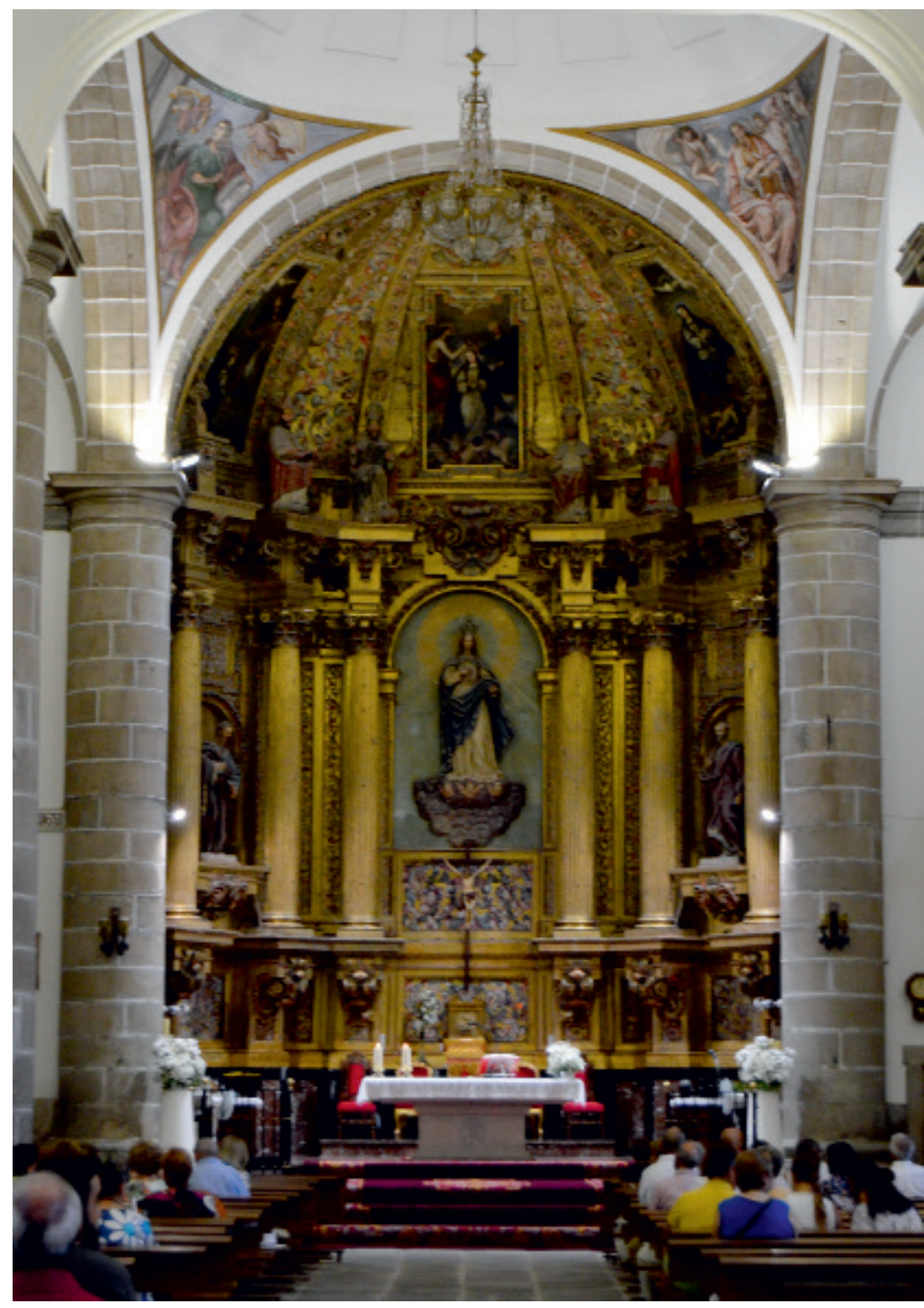

Fig. 5. Retablo mayor de la iglesia parroquial de Navalcarnero (Madrid). Fotografía de la autora.

Madrid al autor de las trazas para el retablo en los círculos cortesanos. En este sentido, podría ser revelador el contrato de los doradores del retablo una vez concluido, en 1677.

El 18 de marzo de 1677 María Antonia de Molina, mujer de Alonso Fernández y doña Mariana de Valenzuela, mujer de Francisco de Haro, ambos maestros doradores y estofadores, contrataron ante notario en Madrid en nombre de sus maridos el dorado del retablo mayor del convento de Uclés ${ }^{29}$. Los fiadores de este contrato fueron el propio pintor del rey y autor del cuadro central Francisco Rizi, Juan de Lobera e Ignacio Fox, maestros en arquitectura vecinos de Madrid. Según esta obligación, los doradores se comprometían a dar la obra por concluida dentro

${ }^{29}$ Obligación del dorado y estofado del retablo mayor del convento de Santiago de Uclés. Madrid, 18 de marzo de 1677 ANU, Libro 42, doc. 1, fol. 21r. 
de un año y medio, a contar desde el día de la Pascua de Resurrección, por 9400 ducados de vellón ${ }^{30}$. El 23 de marzo se presentaron en el convento de Uclés las fianzas de Rizi, Lobera y Fox para el dorado del retablo en el convento, conforme a unas condiciones que detallaban entre otras cosas las calidades del yeso o el dorado, especificándose que el oro empleado debía ser de veintitrés quilates, "el mejor y más subido de color que uviere", mientras que el pedestal y las pilastras estucables y el sotabanco, irían estofados y coloreados a punta de pincel ${ }^{31}$. Estas condiciones nos confirman que el cuadro de Santiago estaba ya colocado en el retablo, como también lo estaba el grupo escultórico del calvario del ochavo del retablo ${ }^{32}$.

Cruz Yábar, que estudió en su tesis doctoral la obra artística de Sebastián de Benavente, ante la comparación formal de los retablos de Torrejón de Velasco, al que considera de la mano de Benavente y el de Uclés atribuye la traza del segundo a este mismo autor. Sin embargo, y a pesar de lo abrumador de la comparativa entre ambos ejemplos, la ausencia total de documentación al respecto y los datos documentales expuestos nos hacen plantear otra posible hipótesis.

Creemos que la presencia de Juan de Lobera e Ignacio Fox junto a Rizi en la firma del contrato no debe ser casual. Juan de Lobera destacó como diseñador de retablos en el área madrileña y toledana ${ }^{33}$. Lobera, arquitecto y ensamblador de origen aragonés se estableció en Madrid al menos desde 1655, participando en la construcción de algunos retablos destacados de la ciudad, como el de la capilla de San Isidro que había trazado José de Villareal o dando trazas para el de la parroquia de San Andrés en $1659^{34}$. Algunos, como el retablo mayor de la parroquial de Navalcarnero (diseñado por Juan de Lobera en torno a 1664) presentan además una notable similitud con el de Uclés ${ }^{35}$. Como su compañero, Fox también es otro conocido retablista del ámbito madrileño de la época, participando en obras como los retablos colaterales de la iglesia de Monserrat de Madrid ${ }^{36}$.

Para justificar la presencia de los arquitectos de retablos Lobera y Fox durante el contrato de los doradores, Cruz Yabar plantea la posibilidad de que García Dardero hubiera muerto poco después de contratar el retablo dejando únicamente concluido el banco y cuerpo central del retablo y que hubieran sido Lobera y Fox los encargados de proseguir la obra ${ }^{37}$. Sin embargo, la documentación es clara al respecto y sabemos que García Dardero concluyó la obra que le había sido encomendada. La presencia de Lobera y Fox por tanto, quedaría justificada junto con Rizi si realmente formaron parte del proceso de diseño del mismo. Por último, la comparativa formal entre el retablo trazado por Lobera de Navalcarnero y el retablo de Uclés muestra una singular e

30 "En la villa de Madrid a diez y ocho días del mes de março año de mil seisçientos y setenta y siete ante mí el presente escrivano y testigos parecieron don Francisco Riçi, pintor de su Magestad y Juan de Lovera y Ygnacio Fox maestros en arquitectura vecinos desta dicha villa todos tres juntamente de mancomun ynsolidum [...] dixeron que Francisco de Haro y Alonso Fernández maestros de doradores y estofadores vecinos de esta dicha villa están convenidos y concertados con el sacro y real convento de Santiago de la villa de Uclés de dorarle y estofarle un retablo en él y acabarle en toda perfecçión dentro de año y medio o en el tiempo que ajustan empeçándolo a haçer desde el día de Pasqua de resurectión que viene deste presente año ocho días más o menos y todo ello en preçio de nueve mil y quatrocientos ducados de vellón con çiertas calidades condiciones". Copia del documento por el que se presentan como fiadores de la obra del retablo Francisco Rizi, Juan de Lobera e Ignacio Fox. Madrid, 18 de marzo de 1677. ANU, Libro 42, doc. 1, fol. 24r. No tenemos mucha información sobre estos doradores, si bien sabemos que Alonso Fernández debe corresponderse con el autor del dorado del retablo de Nuestra Señora del Milagro de las Descalzas Reales, comisionado por Don Juan José de Austria. Cruz, 2003: 84. En la decoración de esta capilla también intervino como pintor para Juan José de Austria Francisco Rizi. González, 1999: 583-589.

31 Condiciones del dorado y estofado del retablo mayor de Uclés, recogidas en la reunión del capítulo del convento el 23 de marzo de 1677. ANU, Libro 42, doc. 1 fol. 29r.

32 Condiciones del dorado y estofado del retablo mayor de Uclés, recogidas en la reunión del capítulo del convento el 23 de marzo de 1677. ANU, Libro 42, doc. 1, fol. 29v. "yten es condizión que el tablero del respaldo del Santo Cristo se a de pintar un Jerusalén".

33 Una panorámica sobre la vida y obras de Juan de Lobera en: Tovar, 1975: 265-282 y Tovar, 1983.

34 Pérez, 2002: 69.

35 Allende, 1915: 185-186. Revenga, 1998: 245.

36 Agulló, 2003: 35. Agulló, 1978: 68.

37 Cruz, 2003: 391. 


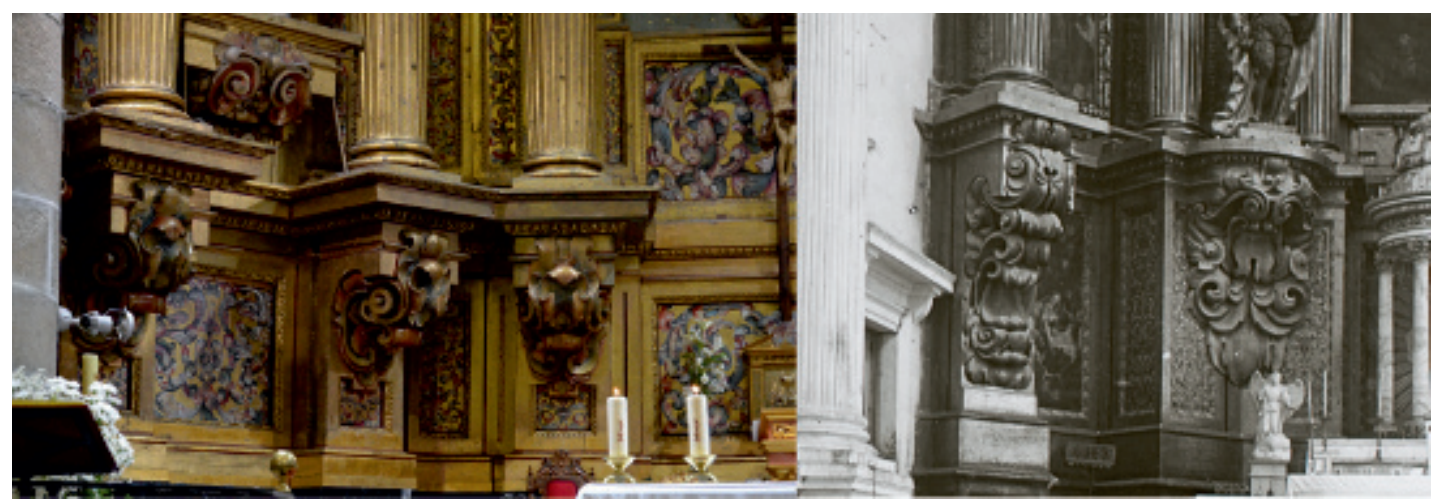

Fig. 6. Detalle de los retablos mayores de Navalcarnero y Uclés.

interesante forma de componer los basamentos de las columnas, casi suspendidas en el aire sustentadas por potentes elementos vegetales incrustados en la propia arquitectura del mueble (fig. 6), algo poco habitual en modelos similares.

\section{Las esculturas}

Si las condiciones del dorado del retablo se cumplieron, este debió estar prácticamente concluido a mediados de 1678. A lo anteriormente descrito, se añadirían elementos escultóricos que completarían la imagen final del mismo. En este sentido, es muy interesante la descripción que de la iglesia ofrecen a finales de 1719 los visitadores de la Orden a la que ya hemos hecho referencia. Nos resulta especialmente valiosa esta visita, ya que es la primera realizada bajo la administración de la Orden de Santiago por parte de un rey Borbón, lo que la convirtió en una de las visitas más exhaustivas en cuanto a la descripción de las dependencias y en las que precisamente se incluye la única descripción del retablo perfectamente concluido. Los visitadores, lejos de los prejuicios académicos de los que harían gala algunos años después Ponz o Ceán describen cómo sobre las columnas del retablo se sostenía una cornisa "muy hermosa", sobre la cual se levantaban seis pedestales dorados en consonancia con las columnas sobre los cuales, aparecían las esculturas a tamaño natural y sentadas de los Apóstoles San Pedro, San Pablo, San Andrés, San Bartolomé, San Juan y San Mateo ${ }^{38}$. Este tipo de elementos escultórico, desconocidos en Uclés hasta la fecha, pueden verse en otros ejemplos de retablos ya aludidos, como el retablo de Navalcarnero o Torrejón de Velasco (figs. 4 y 5), siendo quizá estos apóstoles, como en el caso de Torrejón de Velasco, esculturas en las que solo era de talla la cabeza, manos y atributos, siendo el resto realizado por un armazón de lienzos pintados y encolados ${ }^{39}$. Estas figuras escultóricas de Uclés, que estarían concebidas desde el inicio del proyecto dentro de la estructura del retablo, desaparecerían en algún momento de la historia anterior a las fotografías conservadas. En realidad, las peanas, descontextualizadas en las imágenes fotográficas, se conciben como una interesante solución por parte del tracista a la hora de resolver la considerable altura del ábside, ya que, mediante su inclusión, se consigue llegar hasta la base del cuarto de esfera sin necesidad de alargar las columnas del retablo. Los Apóstoles en bulto redondo y sentados en estas peanas, observarían a los fieles desde la gloria celestial, haciéndoles olvidar la excesiva verticalidad de un ábside que había sido concebido todavía bajo los parámetros tardogóticos.

\footnotetext{
38 Visita al convento de Uclés, 1719. AHN, Órdenes Militares, Libro 1128c, fol.9r.-9v.

39 Martín, 1942: 22. Agradezco a don Carlos, párroco de Torrejón de Velasco el facilitarme la imagen del antiguo retablo de la villa.
} 
La conclusión del retablo llegó cuando a las ya descritas pinturas y esculturas, se sumarían otras dos imágenes de bulto redondo y tamaño natural de San Agustín y San Francisco de Borja enviadas desde Valencia entre 1713 y $1716^{40}$. La inclusión de estos dos santos en el retablo mayor de Uclés hace referencia a la propia historia sacra del convento y la Orden. En el retablo, San Agustín aparecerá redactando la regla sobre la que se inspirará la Orden de Santiago mientras que la figura de San Francisco de Borja combina la faceta militar del noble, perteneciente a la Orden de Santiago con el tipo iconográfico más conocido del santo, contemplativo ante la calavera coronada. Esta última imagen de la desaparecida escultura, hasta ahora desconocida, pertenece a un tipo de representación del santo poco habitual, que encontraremos años más tarde en la escultura de Roberto Michel en las Comendadoras de Santiago de Madrid ${ }^{41}$. Por lo que respecta a la llegada de estas dos imágenes, las fechas, inmediatamente después a la Guerra de Sucesión entre austracistas y borbones y el hecho de buscarlas en un centro artístico tan alejado como Valencia, nos hace pensar el que hubiera una razón de peso que motivara el encargo. Es posible, que estas esculturas fueran encargadas al obrador de uno de los más destacados escultores de la época en el ámbito valenciano, como pudiera ser Leonardo Julio Capuz, autor de numerosas esculturas para retablos levantinos. Así parece atestiguarlo el movimiento de las figuras de San Agustín como de San Francisco de Borja y el tratamiento de sus ropajes airosos en la línea del barroquismo berniniesco del valenciano ${ }^{42}$.

Con la inclusión de estas esculturas, el retablo mayor de Uclés se dio por concluido, permaneciendo en estas condiciones hasta principios del siglo XX, cuando fue fotografiado por estudiosos como Aurelio de Colmenares, Ricardo de Orueta o Pelayo Quintero ${ }^{43}$. Durante algo más de dos centurias, el gran retablo presidió el templo de la casa madre de los santiaguistas hasta que durante la Guerra Civil y posguerra fue reducido a fragmentos y cenizas. El viajero que hoy visite Uclés se encontrará con una réplica en escayola bastante verosímil del desaparecido retablo, realizado por el escultor Julián Alangua durante las obras de rehabilitación del conjunto monástico que a mediados del siglo XX dirigía el arquitecto Antonio Camuñas ${ }^{44}$. Inexplicablemente el cuadro central de Santiago de Francisco Rizi sorteó el expolio y por fortuna puede verse hoy de nuevo presidiendo el ábside de la iglesia.

\section{BIBLIOGRAFÍA}

Agulló y Cobo, Mercedes (1978): Documentos sobre escultores, entalladores y ensambladores de los siglos XVI al XVIII. Valladolid: Universidad de Valladolid, Departamento de Historia del Arte.

Agulló y Cobo, Mercedes (2003): "El convento de San Diego de Alcalá". En: Cuadernos de arte y e iconografia, Tomo 12, 23, pp. 7-76.

Allende Salazar, Juan (1915): “José Antolinez”. Boletín de lo Sociedad Española de Excursiones, pp. 185-186.

Angulo, Diego (1962): "Francisco Rizi. Cuadros religiosos posteriores a 1670 y sin fechar". En: Archivo Español de Arte, Tomo 35, 138, pp. 95-122.

Buchón Cuevas, Ana María (2006): Ignacio Vergara y la escultura de su tiempo en Valencia. Valencia: Generalitat Valenciana.

Cruz Yábar, Juan María (2005): "Los retablos de la parroquia de Santiago de Madrid. Pedro de la Torre, Sebastián de Benavente y Alonso Cano". En: Anales del Instituto de Estudios Madrileños, Vol. XLV, pp. 155-177.

40 AHN, AHT, Leg. 7054. Año 1716. Don Manuel de Gamboa, mayordomo de obras señala que "la administración de los vienes de este convento es muy buena y a abido aumento en este trienio en el qual no han cesado las obras que todas o las más han corrido por su mano pues se hizo alcance en la iglesia dos pilas grandes de alabastro para agua bendita dos estatuas grandes que se trajeron de Valencia de San Agustín y San Francisco de Borja el quarto nuebo que ya se puede avitar, rejas y balcones, la escalera para el servicio de toda la casa con barandillas".

41 Rincón, 2011: 421.

42 Buchón: 2006: 50.

${ }^{43}$ Quintero: 1904: 65.

44 Trabajos en la ejecución del retablo mayor de la iglesia. Madrid, 4 de septiembre de 1953. Archivo General de la Administración, Sig. 1987 T0. Agradezco a la ucleseña Ana María Gálvez toda la información y recuerdos que amablemente me ha trasmitido sobre el desaparecido retablo. 
Cruz Yábar, Juan María (2013): El arquitecto Sebastián de Benavente (1619-1689) y el retablo cortesano de su época. Tesis doctoral inédita presentada en la Universidad Complutense de Madrid.

Díaz Moreno, Félix (2008): “Alonso Cano y el retablo de San Francisco en la Iglesia de Santiago de Madrid”. En: Anales de Historia del Arte. Vol. extraordinario, pp. 279-289.

González Asenjo, Elvira (1999): “Artífices y tasadores de la capilla de Nuestra Señora de la Concepción, más conocida como capilla del Milagro de las Descalzas Reales (1678)". En: Archivo Español de Arte, Tomo 288, pp. 583-589.

González, María del Carmen/Aramburu-Zabala, Miguel Ángel/ Alonso, Begoña/ Polo, Julio Juan (1991): Artistas Cántabros en la Edad Moderna. Su aportación al arte hispánico. Santander: Universidad de Cantabria.

Herrera García, Francisco Javier (2012): "De mármoles mixtos y coloreados. El proyecto de retablo mayor para la Capi1la Real de Sevilla (1683-1694) y su debate internacional”. En: Anuario del Departamento de Historia y Teoría del Arte, Vol. 24, pp. 49-68.

Igual Úbeda, Antonio (1953): Leonardo Julio Capuz. Escultor valenciano del siglo XVIII. Valencia: Institución Alfonso el Magnánimo, 1953.

Lamas-Delgado, Eduardo (2013): “Sebastián Muñoz, Ruiz de la Iglesia y Francisco Rizi: Un nuevo ejemplo de la circulación de modelos en la pintura de la segunda mitad del siglo XVII en Madrid". En: Archivo Español de Arte, Tomo 86, 344, pp. 345-362.

Llaguno Amírola, Eugenio / Ceán Bermúdez, Agustín (1829): Noticias de los arquitectos y architectura de España desde su restauración, Vol. 4. Madrid: Imprenta Real.

Marías, Fernando (1985): Arquitectura del Renacimiento en Toledo (1541-1631), vol. II. Madrid: Instituto Provincial de Investigaciones y Estudios Toledanos.

Marías, Fernando (1986): Arquitectura del Renacimiento en Toledo (1541-1631), vol. III. Madrid: Instituto Provincial de Investigaciones y Estudios Toledanos.

Martín Mayobre, Ricardo (1942): "Un retablo destruido". En: Revista de la Sociedad Española de amigos del Arte. Tomo XIV, Madrid, pp. 21-27.

Marqués del Saltillo (1953): “Artistas madrileños”. En: Boletín de la Sociedad Española de excursiones, Vol. 57.

Madruga Real, Ángela (1974): "Los Zumbigo, familia de arquitectos del siglo XVII". En: Archivo Español de Arte, Tomo 47, 187, pp. 338-342.

Madruga Real, Ángela (1983): Arquitectura barroca salmantina. Las Agustinas de Monterrey. Salamanca: Centro de Estudios Salmantinos.

Nicolau Castro, Juan (2008): "El desaparecido retablo de la parroquial de la villa de Orgaz y sus pinturas de Francisco Rizi”. En: In Sapientia Libertas: Escritos en homenaje al profesor Alfonso E. Pérez Sánchez. Madrid-Sevilla: Museo Nacional del Prado; Fundación Focus-Abengoa, pp. 471-474.

Pérez de Castro, Ramón (2000): “Actividad artística y talleres de ensamblaje en Medina de Rioseco (1650-1675). Lucas González”. En: Boletín del Seminario de Estudios de Arte y Arqueología, Núm. 66, pp. 269-290.

Pérez Sánchez, Alfonso (1986): Carreño, Rizi, Herrera y la pintura madrileña de su tiempo (1650-1700). Madrid: Museo del Prado.

Pérez Sánchez, Alfonso (2002): "Retablos madrileños del siglo XVII”. En: Cámara, Alicia/ Camacho, Santiago (coords). Retablos de la Comunidad de Madrid. Madrid: Dirección General de Patrimonio Histórico, pp. 59-76.

Ponz, Antonio (1777): Viaje a España. Tomo III. Madrid: Imprenta de Joaquín Ibarra.

Revenga Domínguez, Paula (1998): "Precisiones documentales sobre el retablo mayor de la iglesia parroquial de Navalcarnero". En: Anales de Historia del Arte, 8, pp.245-256.

Quintero, Pelayo (1904): Uclés. Antigua residencia de la Orden de Santiago. Madrid: Imprenta de Fortanet.

Ravé Prieto, Juan Luis. (1997): "La obra seiscentista de San Agustín de Marchena". En: Actas de las III Jornadas de Historia de Marchena. Marchena: Ayuntamiento de Marchena, pp. 255-326.

Rincón, Wifredo (2011): "Iconografía de san Francisco de Borja en el arte español”. En: García Hernán, Enrique/ Ryan, María del Pilar (coords.): Francisco de Borja y su tiempo. Política, religión y cultura en la Edad Moderna. ValenciaRoma: Albatros Ediciones e Instituto Historicum Societatis Iesu, pp. 415-438.

Rodríguez G. De Ceballos (1987-1988-1989): "El retablo barroco en Salamanca: materiales, formas, tipologías". En: Imafronte, 3, 4 y 5, pp. 225-258.

Rodriguez Martín, José María (1988): El arquitecto toledano Bartolomé Sombigo y Salcedo (1620-1682). Talavera de la Reina: Nupredsa-La Voz del Tajo.

Tormo, Elías (1931): “A Toledo por las tardes: El museo catedralicio". En: Boletín de la Academia de la Historia, Tomo 99, Cuaderno II, pp.415-458.

Tovar, Virginia (1975): Arquitectos madrileños de la segunda mitad del siglo XVII. Madrid: Instituto de estudios madrileños, 265-282.

Tovar, Virginia (1983): Arquitectura madrileña del siglo XVII. Datos para su estudio. Madrid: Instituto de estudios madrileños.

Urrea, Jesús (1978): “Una nueva obra de Francisco Rizi”. En: Boletín del Seminario de Estudios de Arte y Arqueología, Tomo 44, pp. 500-502.

Fecha de recepción: 05-IX-2017

Fecha de aceptación: 15-XII-2017

Archivo Español de Arte, vol. XCI, n. ${ }^{\circ}$ 364, pp. 381-394, octubre-diciembre 2018 ISSN: 0004-0428, eISSN: 1988-8511, https://doi.org/10.3989/aearte.2018.23 